\title{
Development of a duplex real-time PCR method for the detection of influenza $C$ and $\mathrm{D}$ viruses
}

\author{
Letian Zhang, Meng Lu, Jiaxuan Lu, Ningning Wang, Zhongzhou Pan and Shuo Su*
}

\begin{abstract}
Influenza viruses are major respiratory pathogens known to infect human and a variety of animals and are widely prevalent worldwide. Genome structure of influenza D virus (IDV) is identical to that of influenza C virus (ICV), and phylogenetic analyses suggest that IDV and ICV share a common ancestry and high homology. To date, the prevalence of ICV and IDV in China is unclear, but these viruses represent a potential threat to public health due to cross-species transmission and zoonotic potential. To efficiently monitor ICV and IDV, it is necessary to establish a dual detection method to understand their prevalence and conduct in-depth research. A duplex real-time PCR method for the simultaneous detection of ICV and IDV was developed. TaqMan fluorescent probes and specific primers targeting NP gene of ICV and PBI gene of IDV were designed. This method exhibited good specificity and sensitivity, and the detection limit reached $1 \times 10^{1}$ copies/ $\mathrm{LL}$ of plasmid standards of each pathogen. Thirty-one clinical swine samples and 10 clinical cattle samples were analyzed using this method. One positive sample of IDV was detected, and the accuracy of clinical test results was verified by conventional PCR and DNA sequencing. The duplex real-time PCR detection method represents a sensitive and specific tool to detect ICV and IDV. It provides technical support for virus research and clinical diagnosis of ICV and IDV. This information will benefit animal and human health.
\end{abstract}

Keywords: Influenza C virus, Influenza D virus, Real-time PCR, Multiplex detection

\section{Background}

Influenza viruses belong to the family Orthomyxoviridae, which are single-stranded, negative-stranded, and segmented RNA viruses. Influenza viruses are divided into four types based on the difference between nucleoprotein (NP) and membrane protein (M): influenza A virus (IAV), influenza $B$ virus (IBV), influenza $C$ virus (ICV), and influenza D virus (IDV) (Hause et al. 2014). ICV was first isolated in 1947 (Taylor 1949) and is known to infect humans (Anton et al. 2011; Calvo et al. 2013; Salez

\footnotetext{
* Correspondence: shuosu@njau.edu.cn

Engineering Laboratory of Animal Immunity of Jiangsu Province, College of Veterinary Medicine, Nanjing Agricultural University, Nanjing, China
}

et al. 2014; Thielen et al. 2018). Studies have shown that ICV was an important cause of upper respiratory diseases in children under the age of six and increased the risk of complications of lower respiratory diseases in children under two years of age (Matsuzaki et al. 2006). ICV is frequently coinfected with other viruses and bacterial pathogens, which makes the causal role of ICV uncertain in these cases (Sederdahl and Williams 2020). In addition to infecting humans, ICV has been detected in pigs, cattle, dogs and dromedary camels (Asha and Kumar 2019; Bailey et al. 2018; Guo et al. 1983; Hause et al. 2013; Zhang et al. 2018). It represents a significant public health concern given its pathogenicity in children.

In 2011, IDV was isolated from pigs with influenzalike illness for the first time in the United States, when it

(c) The Author(s). 2021 Open Access This article is licensed under a Creative Commons Attribution 4.0 International License, which permits use, sharing, adaptation, distribution and reproduction in any medium or format, as long as you give appropriate credit to the original author(s) and the source, provide a link to the Creative Commons licence, and indicate if changes were made. The images or other third party material in this article are included in the article's Creative Commons licence, unless indicated otherwise in a credit line to the material. If material is not included in the article's Creative Commons licence and your intended use is not permitted by statutory regulation or exceeds the permitted use, you will need to obtain permission directly from the copyright holder. To view a copy of this licence, visit http://creativecommons.org/licenses/by/4.0/. The Creative Commons Public Domain Dedication waiver (http://creativecommons.org/publicdomain/zero/1.0/) applies to the data made available in this article, unless otherwise stated in a credit line to the data. 
was determined to be an influenza $\mathrm{C}$-like virus based on its similar genetic organization to ICV (Hause et al. 2013). After the first isolation of IDV, it was also detected in cattle, horses and sheep (Murakami et al. 2016; Nedland et al. 2018; Zhai et al. 2017). To date, according to pathological, epidemiological and serological studies, cattle are considered to be the primary natural host for IDV (Collin et al. 2015; Ferguson et al. 2015; Hause et al. 2014), and small ruminants may be a potential host for IDV transmission to other animals (Quast et al. 2015). Bovine respiratory disease (BRD) is the most disastrous disease affecting cattle industry in the United States, and studies have also shown that coinfection by other respiratory viruses along with IDV may cause BRD (Collin et al. 2015; Mitra et al. 2016; Ng et al. 2015). It is worth noting that IDV seropositivity was detected in workers who were in contact with cattle closely on farms (White et al. 2016), and studies have shown that IDV could replicate and spread in ferrets and guinea pigs (Sreenivasan et al. 2015; Yen et al. 2007; Zhu et al. 2013). These results indicated that IDV had a high zoonotic potential. Approximately 50\% homology was noted between emerging IDV and ICV, and no cross-reactivity was found between antibodies against them (Hause et al. 2014).

At present, the prevalence of ICV and IDV in China is unclear. ICV and IDV have been detected in many countries, it is known that ICV and IDV were spread all over the world, so more comprehensive epidemiological investigations and pathogen-related researches are needed (Asha and Kumar 2019). These viruses also have potential significance in terms of public health due to their cross-species transmission and zoonotic potential. Thus, ICV and IDV monitoring using sensitive and practical detection methods is an urgent issue. We chose to develop a duplex real-time PCR method for ICV and IDV based on the excellent performance of real-time PCR in clinical testing. Compared with existing detection methods, the duplex real-time PCR detection method exhibits higher sensitivity and detection efficiency to realize the rapid and efficient identification and detection of ICV and IDV.

\section{Results}

\section{Preparation of plasmid standards}

Concentration of recombinant plasmid ranged from $1 \times$ $10^{7}$ copies $/ \mu \mathrm{L}$ to $1 \times 10^{1}$ copies $/ \mu \mathrm{L}$ based on 10 -fold multiple dilutions. Plasmid standards of each pathogen concentration in the range of $1 \times 10^{7}$ copies $/ \mu \mathrm{L} \sim 1 \times 10^{1}$ copies $/ \mu \mathrm{L}$ were selected for singleplex real-time PCR. The results of the standard curve showed good amplification efficiency and correlation coefficient $\left(\mathrm{ICV} \mathrm{R}^{2}=\right.$ $0.9927, \mathrm{E}$ value $=96 \%$; IDV $\mathrm{R}^{2}=0.9966, \mathrm{E}$ value $=109 \%$ ) (Fig. 1), indicating proper dilution of the plasmid standard.

\section{Optimization of the multiplex reaction system}

To obtain the best amplification efficiency, duplex realtime PCR was performed with probes in final concentrations ranging from $100 \mathrm{nM}$ to $400 \mathrm{nM}$ and primers with final concentrations ranging from $400 \mathrm{nM}$ to $1100 \mathrm{nM}$. Then, the fluorescence intensity and $\mathrm{Cq}$ values of different combinations were compared. ICV plasmid standard at a concentration of $1 \times 10^{7}$ copies/ $\mu \mathrm{L}$ and IDV plasmid standard at a concentration of $1 \times 10^{1}$ copies $/ \mu \mathrm{L}$ were used as templates for reaction. The optimal final concentration of probe was $100 \mathrm{nM}$, and the optimal primer concentration was $400 \mathrm{nM}$ (Table 1).
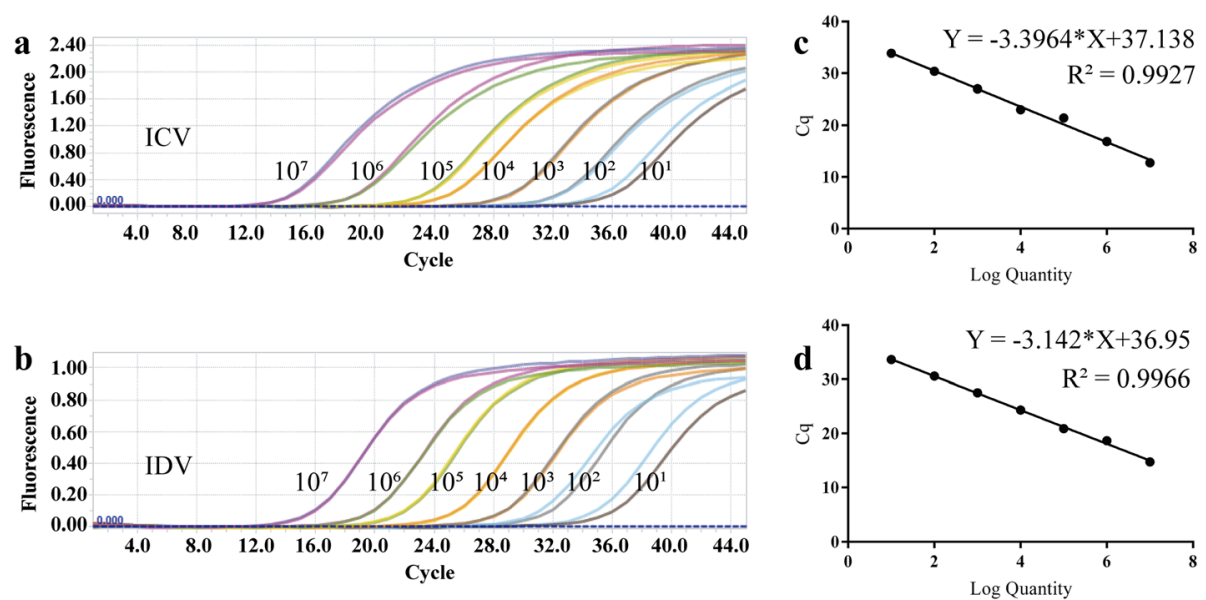

Fig. 1 Preparation of plasmid standards. a, b Amplification curves of ICV and IDV for each plasmid standard at concentrations ranging from $1 \times$ $10^{7}$ copies $/ \mu \mathrm{L}$ to $1 \times 10^{1}$ copies $/ \mu \mathrm{L} ; \mathbf{c}$, $\mathbf{d}$ standard curves of plasmid standards of ICV and IDV. All standard curves were generated using GraphPad Prism 6 software 
Table 1 ICV and IDV detected by duplex real-time PCR assay using different primer concentrations

\begin{tabular}{|c|c|c|c|c|c|}
\hline $\begin{array}{l}\text { Primer } \\
\text { concentration } \\
\text { (nM) }\end{array}$ & $\begin{array}{l}\text { IDV } \\
\text { Cq values }\end{array}$ & $\begin{array}{l}\text { ICV } \\
\text { Cq values }\end{array}$ & $\begin{array}{l}\text { Probe } \\
\text { concentration } \\
\text { (nM) }\end{array}$ & $\begin{array}{l}\text { IDV } \\
\text { Cq values }\end{array}$ & $\begin{array}{l}\text { ICV } \\
\text { Cq values }\end{array}$ \\
\hline 400 & 34.82 & 12.00 & 100 & 34.82 & 13.28 \\
\hline 500 & 36.44 & 12.92 & 150 & 36.44 & 12.90 \\
\hline 600 & 38.21 & 12.73 & 200 & 38.21 & 12.70 \\
\hline 700 & 39.89 & 12.59 & 250 & 39.89 & 12.67 \\
\hline 800 & - & 12.41 & 300 & - & 12.56 \\
\hline 900 & - & 12.38 & 350 & - & 12.45 \\
\hline 1000 & - & 12.49 & 400 & - & 12.49 \\
\hline 1100 & - & 12.55 & 450 & - & 12.63 \\
\hline
\end{tabular}

"-": No signal detected, negative (-), ICV, influenza C virus; IDV, influenza D virus
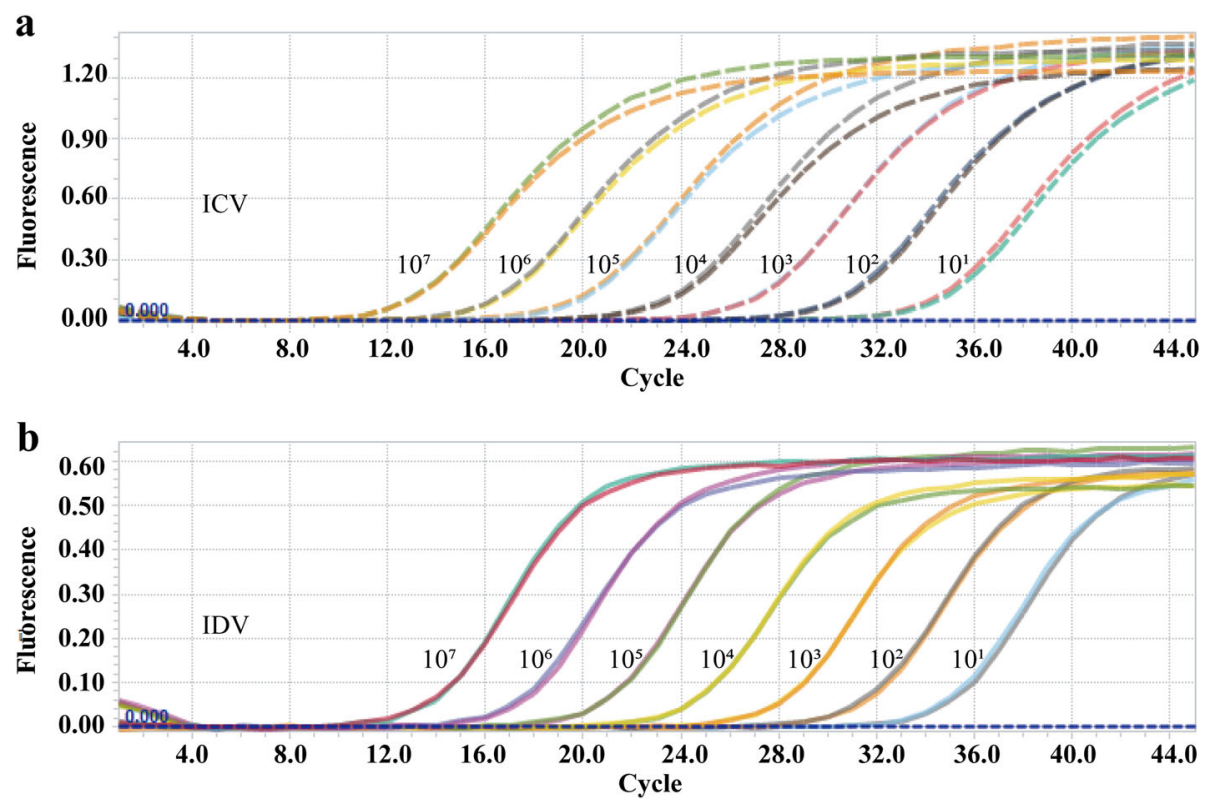

Fig. 2 Sensitivity of duplex real-time PCR assay. $\mathbf{a}$, b Amplification curvesof plasmid standards of ICV and IDV at concentrations ranging from $1 \times$ $10^{7}$ copies/ $\mu \mathrm{L}$ to $1 \times 10^{1}$ copies/ $\mu \mathrm{L}$ detected by duplex real-time PCR

Table 2 Sensitivity test results of duplex real-time PCR assay

\begin{tabular}{lllll}
\hline Pathogen & Concentration & Repeat times & Positive number & Positive rate \\
\hline ICV & $1 \times 10^{2}$ & 15 & 15 & $100 \%$ \\
& $1 \times 10^{1}$ & 15 & 15 & $100 \%$ \\
$1 \times 10^{0}$ & 15 & 13 & $87 \%$ \\
IDV & $1 \times 10^{2}$ & 15 & 15 & $100 \%$ \\
& $1 \times 10^{1}$ & 15 & 9 & $100 \%$ \\
& $1 \times 10^{0}$ & 15 & $60 \%$ &
\end{tabular}

The cutoff line of positivity was automatically decided using a Roche LightCycler ${ }^{\circledast} 96$ Instrument. ICV influenza C virus, IDV influenza D virus 
Table 3 Specificity test results of duplex real-time PCR

\begin{tabular}{|c|c|c|c|c|c|c|c|c|c|c|c|}
\hline \multirow{2}{*}{$\begin{array}{l}\text { Positive } \\
\text { samples }\end{array}$} & \multicolumn{10}{|c|}{ Singleplex conventional PCR detection and DNA sequencing ${ }^{a}$} & \multirow{2}{*}{$\begin{array}{l}\text { Duplex } \\
\text { real-time } \\
\text { PCR } \\
\text { detection }^{b}\end{array}$} \\
\hline & ICV & IDV & JEV & CSFV & IAV & TTsuV1 & TTsuV2 & PRRSV & PCV2 & PCV3 & \\
\hline ICV & + & - & - & - & - & - & - & - & - & - & + \\
\hline IDV & - & + & - & - & - & - & - & - & - & - & + \\
\hline JEV & - & - & + & - & - & - & - & - & - & - & - \\
\hline CSFV & - & - & - & + & - & - & - & - & - & - & - \\
\hline IAV & - & - & - & - & + & - & - & - & - & - & - \\
\hline TTsuV1 & - & - & - & - & - & + & - & - & - & - & - \\
\hline TTsuV2 & - & - & - & - & - & - & + & - & - & - & - \\
\hline PRRSV & - & - & - & - & - & - & - & + & - & - & - \\
\hline PCV2 & - & - & - & - & - & - & - & - & + & - & - \\
\hline PCV3 & - & - & - & - & - & - & - & - & - & + & - \\
\hline
\end{tabular}

${ }^{a}$ These samples were detected by conventional PCR and confirmed by DNA sequencing. ${ }^{\mathrm{b}}$ Criteria of positivity: Cq $\leq 38$, invalid (?); Cq $>38$ or no signal detected, negative (-). PCV2 porcine circovirus type 2, PCV3 porcine circovirus type 3, JEV Japanese encephalitis virus, CSFV classical swine fever virus; IAV influenza A virus, $\Pi$ TsuV1 Torque teno sus virus $1, \Pi$ suV2 Torque teno sus virus 2, PRRSV porcine reproductive and respiratory syndrome virus, ICV influenza $C$ virus, IDV influenza D virus

\section{Effectiveness of duplex real-time PCR assay}

In this study, effectiveness of duplex real-time PCR detection method was assessed in terms of sensitivity, specificity and repeatability.

For sensitivity testing, plasmid standards of ICV and IDV at concentrations of $1 \times 10^{7}$ copies $/ \mu \mathrm{L}$ to $1 \times 10^{1}$ copies $/ \mu \mathrm{L}$ were detected using the optimized system. Results showed that samples with the lowest concentration of $1 \times 10^{1}$ copies $/ \mu \mathrm{L}$ could be identified as positive using this method (Fig. 2). Repeated tests showed $100 \%$ positivity in plasmid sample with concentration of $1 \times 10^{1}$ copies $/ \mu \mathrm{L}$. However, strong instability in plasmid sample with concentration of $1 \times 10^{\circ}$ copies $/ \mu \mathrm{L}$ was noted, and the positive rate was less than $90 \%$. Therefore, $1 \times 10^{1}$ copies $/ \mu \mathrm{L}$ is the detection limit of this duplex real-time PCR detection method (Table 2). Sensitivity test results showed that this method has excellent sensitivity, facilitating the detection of ICV and IDV in clinical samples with low viral concentrations.

To assess the specificity, the optimized method was used to detect ICV and IDV in samples positive for porcine circovirus type 2 (PCV2), porcine circovirus type 3 (PCV3), Japanese encephalitis virus (JEV), classical swine fever virus (CSFV), IAV, Torque teno sus virus 1 (TTsuV1), Torque teno sus virus 2 (TTsuV2) and porcine reproductive and respiratory syndrome virus (PRRS $\mathrm{V})$, RNase-free water was used as a negative control (Table 3). The results showed that the target pathogens were detected, and negative results were obtained for all other pathogens, indicating that this method exhibits good specificity. The viruses selected for specific testing can cause respiratory diseases of the host. Pigs are cohosts of ICV and IDV. Thus, the possibility of coinfection in clinical samples necessitates the need for an assay that can differentiate between these viruses. The results of specificity test demonstrated that this method has the ability to specifically detect ICV and IDV in clinical samples coinfected with other viruses.

Regarding repeatability testing, three replications were performed in triplicate for the analysis of intra-assay and interassay variability, and the coefficient of variation was calculated. As showed in Table 4, coefficient of variation $(\mathrm{CV}, \%)$ values of $\mathrm{Cq}$ values were all less than $2 \%$,

Table 4 Repeatability results of duplex real-time PCR assay

\begin{tabular}{|c|c|c|c|c|c|}
\hline \multirow[t]{2}{*}{ Plasmid } & \multirow[t]{2}{*}{ Concentration } & \multicolumn{2}{|c|}{ Intra-assay Cq value } & \multicolumn{2}{|c|}{ Interassay $\mathrm{Cq}$ value } \\
\hline & & Mean $\pm S D^{a}$ & CV\% & Mean \pm SD & CV\% \\
\hline \multirow[t]{7}{*}{ ICV } & $1 \times 10^{7}$ & $13.26 \pm 0.26$ & 1.96 & $13.79 \pm 0.26$ & 1.91 \\
\hline & $1 \times 10^{6}$ & $16.65 \pm 0.16$ & 0.96 & $16.86 \pm 0.22$ & 1.33 \\
\hline & $1 \times 10^{5}$ & $20.41 \pm 0.06$ & 0.29 & $20.54 \pm 0.13$ & 0.65 \\
\hline & $1 \times 10^{4}$ & $24.45 \pm 0.08$ & 0.33 & $24.03 \pm 0.24$ & 0.99 \\
\hline & $1 \times 10^{3}$ & $27.51 \pm 0.02$ & 0.07 & $27.55 \pm 0.29$ & 1.06 \\
\hline & $1 \times 10^{2}$ & $31.16 \pm 0.1$ & 0.32 & $31.86 \pm 0.21$ & 0.67 \\
\hline & $1 \times 10^{1}$ & $34.51 \pm 0.06$ & 0.17 & $34.51 \pm 0.39$ & 1.12 \\
\hline \multirow[t]{7}{*}{ IDV } & $1 \times 10^{7}$ & $15.03 \pm 0.1$ & 0.67 & $15.42 \pm 0.25$ & 1.63 \\
\hline & $1 \times 10^{6}$ & $18.23 \pm 0.03$ & 0.16 & $18.93 \pm 0.27$ & 1.43 \\
\hline & $1 \times 10^{5}$ & $21.73 \pm 0.18$ & 0.83 & $21.74 \pm 0.15$ & 0.68 \\
\hline & $1 \times 10^{4}$ & $25.03 \pm 0.25$ & 1 & $26.02 \pm 0.22$ & 0.84 \\
\hline & $1 \times 10^{3}$ & $28.62 \pm 0.32$ & 1.11 & $29.26 \pm 0.26$ & 0.87 \\
\hline & $1 \times 10^{2}$ & $32.03 \pm 0.05$ & 0.16 & $32.14 \pm 0.21$ & 0.66 \\
\hline & $1 \times 10^{1}$ & $32.89 \pm 0.21$ & 0.64 & $34.74 \pm 0.53$ & 1.52 \\
\hline
\end{tabular}

a SD Standard Deviation, CV coefficient of variation 

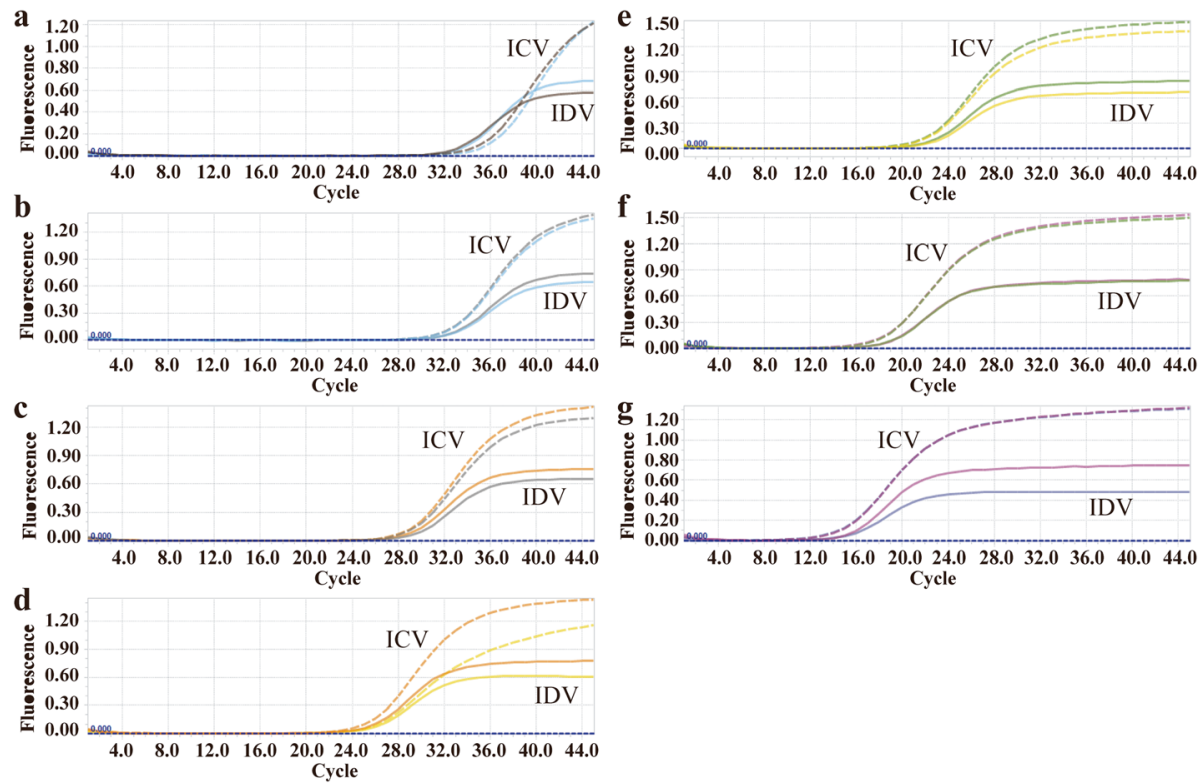

Cycle

Fig. 3 Coinfection simulation experiments performed with mixed templates at the same concentrations. a-g Amplification curves of ICV + IDV at concentrations ranging from $1 \times 10^{7}$ copies $/ \mu \mathrm{L}$ to $1 \times 10^{1}$ copies $/ \mu \mathrm{L}$ were used in these experiments. Two replicates were included per reaction.

demonstrating that this method is stable and exhibits good repeatability.

\section{Coinfection simulation test}

Coinfection simulation experiment was performed using $1 \times 10^{7}$ copies $/ \mu \mathrm{L} \sim 1 \times 10^{1}$ copies $/ \mu \mathrm{L}$ plasmid standards at the same concentration. (Fig. 3). The performance to identify clinical samples with similar concentrations of two viruses was simulated. Another coinfection simulation experiment involved mixing plasmid standards of two pathogens. One standard was present at a concentration of $1 \times 10^{7}$ copies $/ \mu \mathrm{L}$, and the other was present at a concentration of $1 \times$ $10^{1}$ copies $/ \mu \mathrm{L}$ (Fig. 4). The purpose of this
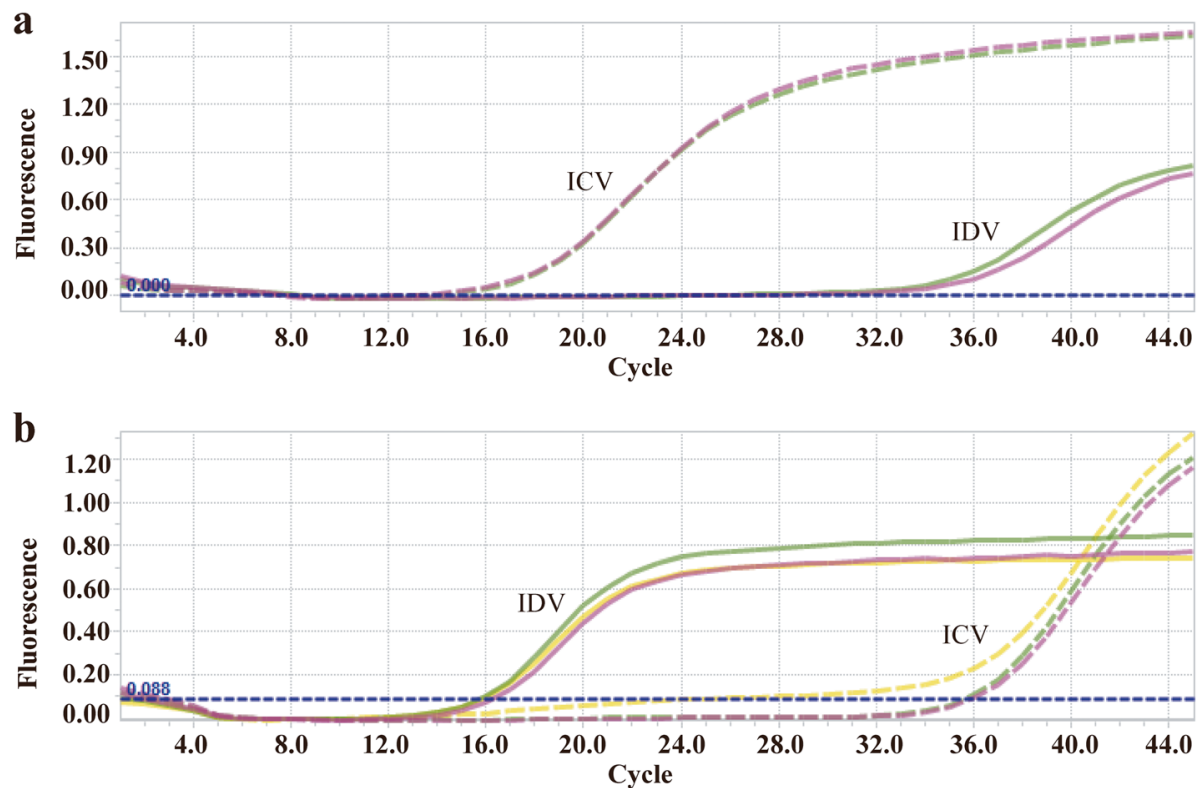

Fig. 4 Coinfection simulation experiments with mixed templates at different concentrations. a Amplification curves of ICV plasmid standard at concentrations of $1 \times 10^{1}$ copies $/ \mu \mathrm{L}+$ IDV plasmid standard at concentrations of $1 \times 10^{7}$ copies $/ \mu \mathrm{L}$. b Amplification curves of ICV plasmid standard at concentrations of $1 \times 10^{7}$ copies $/ \mu \mathrm{L}+$ IDV plasmid standard at concentrations of $1 \times 10^{1}$ copies $/ \mu \mathrm{L}$. 
experiment was to simulate whether a high concentration of one virus would affect the detection of another virus present at a low concentration, given that the concentrations of two viruses can significantly vary in clinical samples. The two coinfection simulation test results suggested that low concentrations of ICV and IDV could be detected in mixed samples.

\section{Clinical sample detection}

The method established in this research was used to assess clinical samples, including 31 nasal swab and lung tissue samples collected from pig farms and 10 nasal swabs and blood samples collected from cattle farms in China, to verify its performance in clinical application. No positive ICV samples were detected, and one positive IDV sample was detected. Conventional PCR primers for $M$ gene of ICV and P42 gene of IDV were designed and synthesized. Then, the conventional PCR was used to assess the clinical samples, the positive samples were underwent DNA sequencing for verification. The positive control samples included lung tissues of pigs with respiratory symptoms that were collected from Guangxi Province in 2019. The detection results obtained using this method were consistent with conventional PCR tests and DNA sequencing, demonstrating that this duplex real-time PCR detection method is effective in clinical detection.

\section{Discussion}

There have been five recorded influenza pandemics since 1900 due to genetic drift and shift and repeated annual seasonal epidemics (Urbaniak and MarkowskaDaniel 2014). The H5N1 strain of IAV was the first recorded strain that has crossed the barrier between animals and humans, resulting in zoonotic fatal infections (Mostafa et al. 2018). Emerging and re-emerging threats of influenza viruses remain a persistent public health challenge. Some studies suggested the potential for cross-species transmission and zoonotic transmission of ICV and IDV (Guo et al. 1983; White et al. 2016; Yuanji and Desselberger 1984). Therefore, clinical surveillance of ICV and IDV is beneficial to virus prevention and public health.

Because both IAV and IBV cause annual epidemics, strict surveillance programs are being implemented worldwide to monitor the slightest changes in genome caused by genetic drift or shift (Khanna et al. 2012; Khanna et al. 2008; Kumar et al. 2018; Taubenberger and Morens 2006; Treanor 2004). ICV and IDV only cause mild upper respiratory symptoms in host, and ICV occasionally causes severe lower respiratory symptoms in children. Thus, ICV and IDV are not considered as clinically important as IAV and thus have not been effectively monitored. Given the lack of effective monitoring data, the prevalence of ICV and IDV in China remains unclear. ICV is distributed worldwide, and serological studies have shown that most humans can develop antibodies against the virus (Salez et al. 2014). One report showed that genetic similarity between porcine ICV and human ICV results in interspecies transmission (Guo et al. 1983; Yuanji and Desselberger 1984). Emerging IDV strains have also shown potential for interspecies transmission and zoonosis. Ferrets are model animals for human influenza virus infection, and studies have shown that IDV can replicate and be transmitted among ferrets (Sreenivasan et al. 2015). Analyses of the zoonotic potential of IDV in people who had occupational contact with cattle revealed that they had a high seroprevalence of IDV (94-97\%). Thus, IDV may have the ability of interspecies transmission (White et al. 2016). Cross-species transmission of the virus poses a significant threat to human and livestock health. (Olival et al. 2017).

Analysis of the maximum-likelihood phylogenetic tree based on PB1 sequences of influenza A, B, C and D viruses revealed that IDV and ICV clustered most closely. Studies have also shown approximately 50\% homology between IDV and ICV, and swine is the common host of ICV and IDV. Thus, it is necessary to identify the two pathogens in samples. Accurate and rapid detection method is an important prerequisite for effective monitoring of ICV and IDV. Nucleic acid detection with good specificity and repeatability offers great advantages in clinical detection; for example, the TaqMan-based realtime PCR method exhibits good specificity and sensitivity (Arya et al. 2005; Heid et al. 1996). In this study, a duplex real-time PCR method was developed to detect ICV and IDV.

The possibility of false-positive results will be increased given the improvement in sensitivity, so contamination should be avoided during sampling and experimental operations. Good operation is necessary to obtain credible results in the laboratory. To avoid interference between primers and probes designed for real-time PCR, the target fragments of ICV and IDV were designed to be similar in size and annealing temperature, and the reaction system was optimized. Finally, the limit of detection (LOD) of this assay were as low as $1 \times 10^{1}$ copies $/ \mu \mathrm{L}$ for both pathogens, and no interference was noted between the two pairs of primers and probes. Faccini et al. developed and evaluated a singleplex real-time PCR detection method that can detected IDV in a short period time with an LOD of 20 copies/ $\mu \mathrm{L}$ (Faccini et al. 2017). Kanti et al. developed a realtime PCR detection method for ICV and used this method to detect ICV infection in human respiratory tract samples from Alberta, Canada (Pabbaraju et al. 2013). Henritzi et al. developed a multiplex real-time PCR method for the detection of influenza A, B, C and D viruses. LOD of this 
method reached $1 \times 10^{1}$ copies $/ \mu \mathrm{L}$ (Henritzi et al. 2019), but the fluorescence intensity decreased obviously when plasmid standards with concentrations of $1 \times 10^{2}$ copies/ $\mu \mathrm{L}$ and $1 \times 10^{1}$ copies $/ \mu \mathrm{L}$ were detected. Thus, this detection method exhibited poor stability in low-concentration samples. Compared with previously reported methods, the duplex real-time PCR detection method developed in this study has better sensitivity and detection efficiency. Given that clinical samples with ICV and IDV coinfection were not detected in this study, a coinfection simulation test was performed. The maximum concentration difference between the two pathogen recombinant plasmids was selected as the template to simulate the possible interference between them in clinical environment. The detection method developed in this study still maintains high sensitivity and specificity when simultaneously assessing different concentrations of two pathogens in the same sample. There are some limitations in this study. Due to the difficulty of obtaining human clinical samples, we were unable to use this method to detect human clinical samples. In addition, no ICV-positive samples were detected.

In summary, ICV and IDV exhibit potential public health significance given the potential for cross-host transmission and zoonosis. At present, ICV and IDV are not effectively monitored in China. The high homology between them makes it necessary to establish a rapid and effective duplex detection method. Thus, a duplex real-time PCR assay for the detection of ICV and IDV was developed. Given the lower LODs, this new detection method with lower false-negative rates than currently available methods facilitates more effective ICV and IDV monitoring. The method can detect duplex pathogens simultaneously in a single reaction, representing a convenient coinfection detection method that is useful for effective clinical detection and scientific research.

\section{Conclusions}

In this study, a TaqMan-based duplex real-time PCR method was developed for the simultaneous detection of ICV and emerging IDV simultaneously. This method had good specificity and repeatability with an LOD as low as $1 \times 10^{1}$ copies $/ \mu \mathrm{L}$ for both pathogens. At present, no efficient method is available to detect ICV and IDV simultaneously. This duplex real-time PCR detection method can be used for the rapid detection of ICV and IDV in a large number of samples in the context of clinical assessments and viral research, which also benefits animal and public health.

\section{Materials and Methods}

\section{Construction of plasmid standards}

RNA of ICV from positive samples was extracted as a template, and the designed primers were used for PCR amplification. Following the manufacturer's instructions,
cDNA of ICV was obtained by reverse transcription using the HiScript III RT SuperMix for qPCR (+gDNA wiper) Kit (Nanjing Vazyme Biotechnology Co., Ltd.), and then target fragments of ICV were amplified via high-fidelity PCR using Phanta Max Super-Fidelity DNA Polymerase (Nanjing Vazyme Biotechnology Co., Ltd.). After the selection of TA colonies and confirmation by DNA sequencing (Sangon Biotech (Shanghai) Co., Ltd.), PCR fragments were cloned into the pMD18-T vector. Sequencing confirmed that the recombinant plasmid pMD18-T-ICV contained an ICV insertion fragment. The recombinant plasmid pUC57-IDV containing IDV targeted fragment was synthesized by Nanjing Genscript Biotech Co., Ltd.

\section{RNA extraction and reverse transcription}

Samples positive for PCV2, PCV3, JEV, CSFV, IAV, TTsuV1, TTsuV2 and PRRSV were stored in our laboratory. Clinical samples collected from 2019 to 2020 were stored at $-80{ }^{\circ} \mathrm{C}$. Nasal swab and lung tissue samples were treated with 3 to 5 volumes of PBS. Then, samples were mixed with supernatant by vortexing and collected after centrifugation at $12,000 \times \mathrm{g}$ at $4{ }^{\circ} \mathrm{C}$ for $15 \mathrm{~min}$. Viral nucleic acids were extracted using the Viral DNA/RNA Kit (Jiangsu Cowin Biotech Co., Ltd.), and the HiScript III RT SuperMix for qPCR (+gDNA wiper) Kit was used to perform reverse transcription following the manufacturer's instructions.

\section{Primers and probes}

All ICV and IDV sequences available in GenBank were analyzed to improve the detection performance of the primers. Finally, we designed primers and probes for the conserved $N P$ and $M$ genes for ICV, and $P B 1$ and $P 42$ genes were chosen for IDV. Among them, ICV-detect-F/ $\mathrm{R}$ and IDV-detect-F/R are two primer pairs used for real-time PCR detection method, and ICV-RT-F/R and IDV-RT-F/R are two primer pairs used for conventional PCR. The specific primers and probes used for the construction of plasmid standards were designed with Oligo 7 ( V. 7.60) (Table 5) and synthesized by Sangon Biotech (Shanghai) Co., Ltd.

Reaction condition optimization for duplex real-time PCR Amplification was performed on a Roche LightCycler ${ }^{\circ}$ 96 Instrument (Roche Life Science) with the following program: $95^{\circ} \mathrm{C}$ for $600 \mathrm{~s}$; 45 cycles of $95^{\circ} \mathrm{C}$ for $10 \mathrm{~s}$, $55^{\circ} \mathrm{C}$ for $10 \mathrm{~s}$, and $72{ }^{\circ} \mathrm{C}$ for $20 \mathrm{~s}$. Fluorescence signals were collected automatically at the end of each cycle. The duplex real-time PCR included the following components: $2 \times$ AceQ qPCR Probe Master Mix (AceQ qPCR Probe Master Mix kit, Nanjing Vazyme Biotechnology Co., Ltd.), primers, probes, and templates for ICV and IDV. To determine the optimal template concentration, 
Table 5 Primer and probe sequences for ICV and IDV

\begin{tabular}{|c|c|c|c|c|}
\hline Primer/Probe & Sequence $5^{\prime}-3^{\prime}$ & Gene & Product size & Position \\
\hline ICV-Detect-F & AAGAGCCATGCAAGGAATTGA & $N P$ & $117 \mathrm{bp}$ & $710-826^{a}$ \\
\hline ICV-Detect-R & TCTGCGATGACATTTAGAGCTTC & & & \\
\hline ICV-Probe & VIC-AAAGCGTTTCCTGGACCTITAA-MGB & & & \\
\hline ICV-RT-F & ATGGGRCGAATGGCDATGAAATGGT & M & $257 \mathrm{bp}$ & $731-987^{\mathrm{a}}$ \\
\hline ICV-RT-R & TCCCATCTGCCRAGYACAAAACC & & & \\
\hline IDV-Detect-F & СCCTCCTACAGGAACAGAGTITC & PB1 & $124 \mathrm{bp}$ & $1880-2003^{b}$ \\
\hline IDV-Detect-R & GCGTTGATACAACTGCCTCG & & & \\
\hline IDV-Probe & FAM-AGGAACCCCTITACACAGTTTGAGAAGACAG-BHQ1 & & & \\
\hline IDV-RT-F & GTGGTGCACATATGCCTGAG & P42 & $487 \mathrm{bp}$ & $169-655^{\mathrm{b}}$ \\
\hline IDV-RT-R & CCATTGCTCTTGAYCCATAYGC & & & \\
\hline
\end{tabular}

${ }^{\mathrm{a}}$ GenBank accession NC_006311.1; ${ }^{\mathrm{b}}$ GenBank accession NC_036615.1

the duplex reaction system was optimized by using different primer $(10 \mu \mathrm{M})$ and probe $(10 \mu \mathrm{M})$ concentrations. In this stage, we used the primers and probes in the system at concentrations ranging from $400 \mathrm{nM}$ to $1100 \mathrm{nM}$ and $100 \mathrm{nM}$ to $450 \mathrm{nM}$, respectively.

\section{Sensitivity of the duplex real-time PCR assay}

To explore LOD of the duplex real-time PCR method, PCRs for both viruses separately using standard plasmid templates with concentrations ranging from $1 \times 10^{7}$ copies $/ \mu \mathrm{L}$ to $1 \times 10^{1}$ copies $/ \mu \mathrm{L}$ were performed. At this stage, result is only considered the presumable LOD. To confirm LOD value, a duplex real-time PCR was performed using plasmid templates at the concentration of the presumable LOD, tenfold and 1/10 concentration of the presumable LOD with 15 replicates for each concentration. The lowest concentration that was consistent with the positive detection rate of $\geq 95 \%$ was regarded as the reliable LOD.

\section{Specificity of the duplex real-time PCR assay}

To exclude potential false-positive results caused by other viruses that may be present in the sample, duplex real-time PCR detection method was used to detect ICV and IDV standard plasmids and other respiratory viruspositive samples preserved in our laboratory, including PCV2, PCV3, JEV, CSFV, IAV, TTsuV1, TTsuV2 and PRRSV. RNase-free water was served as a negative control.

\section{Repeatability of the duplex real-time PCR assay}

Duplex real-time PCR using the standard plasmids of ICV and IDV at concentrations ranging from $1 \times 10^{7}$ copies $/ \mu \mathrm{L}$ to the LOD was performed with three replicates for each reaction. The experiment was repeated thrice with a seven-day interval between replicates. The same concentrations of ICV and IDV standard plasmids were mixed to form the detection template. To evaluate the repeatability, CV of Cq values was calculated for different concentrations of virus in samples based on the three tests.

\section{Standard sample simulated coinfection test}

Coinfection with two pathogens may be encountered in clinical testing. To simulate actual coinfection events, two types of simulation experiments were performed. First, the same concentrations of plasmid standards of ICV and IDV were mixed as templates and detected using the duplex real-time PCR assay. The standard plasmid of each pathogen at concentrations ranging from $1 \times 10^{7}$ copies $/ \mu \mathrm{L}$ to the LOD was tested. In another simulation experiment, different concentrations of standard samples were combined. The plasmid standard of one pathogen at a concentration of $1 \times 10^{7}$ copies $/ \mu \mathrm{L}$ and the other at the LOD were mixed. Then, sample mixture was assessed using the duplex real-time assay.

\section{Clinical sample detection}

We tested 31 nasal swab and lung tissue samples collected from pigs using duplex real-time method. Clinical performance of this methods was evaluated by comparing the results with those of conventional PCR and DNA sequencing. DNA sequencing was performed by Sangon Biotech (Shanghai) Co., Ltd. to confirm positive samples detected using this detection method.

\footnotetext{
Acknowledgments

We would like to thank Prof. Jiyong Zhou for his guidance and support to our research, and thank the Bioinformatics Center of Nanjing Agricultural University for technical supports.
}

Authors' contributions

S.S. and P.Z.Z. were involved in the experimental design and provided guidance on the experimental operation. Z.L.T., L.M., L.J.X. and W.N.N. performed the experiments and data analysis. All authors contributed to writing the manuscript. All authors have read and approved the final version of the manuscript. 


\section{Funding}

This work was financially supported by the National Key Research and Development Program of China (2017YFD0500101) and the Fundamental Research Funds for the Central Universities (Y0201900459).

\section{Availability of data and materials}

The datasets during and/or analyzed during the current study are available from the corresponding author on reasonable request.

\section{Declarations}

Ethics approval and consent to participate

Not applicable.

\section{Consent for publication}

Not applicable.

\section{Competing interests}

The authors declare no competing financial interest.

Received: 5 May 2021 Accepted: 8 July 2021

Published online: 14 September 2021

\section{References}

Anton, A., M.A. Marcos, F.M. Codoner, P. De Molina, A. Martinez, N. Cardenosa, P. Godoy, N. Torner, M.J. Martinez, S. Ramon, et al. 2011. Influenza C virus surveillance during the first influenza A (H1N1) 2009 pandemic wave in Catalonia, Spain. Diagnostic Microbiology and Infectious Disease 69 (4): 419427. https://doi.org/10.1016/j.diagmicrobio.2010.11.006.

Arya, M., I.S. Shergill, M. Williamson, L. Gommersall, N. Arya, and H.R. Patel. 2005. Basic principles of real-time quantitative PCR. Expert Review of Molecular Diagnostics 5 (2): 209-219. https://doi.org/10.1586/14737159.5.2.209.

Asha, K., and B. Kumar. 2019. Emerging Influenza D Virus Threat: What We Know so Far! Journal of Clinical Medicine 8 (2). https://doi.org/10.3390/jcm8020192.

Bailey, E.S., J.Y. Choi, J.K. Fieldhouse, L.K. Borkenhagen, J. Zemke, D. Zhang, and G. C. Gray. 2018. The continual threat of influenza virus infections at the human-animal interface: What is new from a one health perspective? Evolution, Medicine, and Public Health 2018 (1): 192-198. https://doi.org/10.1 093/emph/eoy013.

Calvo, C., M.L. Garcia-Garcia, B. Borrell, F. Pozo, and I. Casas. 2013. Prospective study of influenza $C$ in hospitalized children. The Pediatric Infectious Disease Journal 32 (8): 916-919. https://doi.org/10.1097/INF.0b013e31828fca10.

Collin, E.A., Z. Sheng, Y. Lang, W. Ma, B.M. Hause, and F. Li. 2015. Cocirculation of two distinct genetic and antigenic lineages of proposed influenza $D$ virus in cattle. Journal of Virology 89 (2): 1036-1042. https://doi.org/10.1128/JVI.0271 8-14

Faccini, S., A. De Mattia, C. Chiapponi, I. Barbieri, M.B. Boniotti, C. Rosignoli, G. Franzini, A. Moreno, E. Foni, and A.D. Nigrelli. 2017. Development and evaluation of a new Real-Time RT-PCR assay for detection of proposed influenza D virus. Journal of Virological Methods 243: 31-34. https://doi.org/1 0.1016/j.jviromet.2017.01.019.

Ferguson, L., L. Eckard, W.B. Epperson, L.P. Long, D. Smith, C. Huston, S. Genova, R. Webby, and X.F. Wan. 2015. Influenza D virus infection in Mississippi beef cattle. Virology 486: 28-34. https://doi.org/10.1016/j.virol.2015.08.030.

Guo, Y.J., F.G. Jin, P. Wang, M. Wang, and J.M. Zhu. 1983. Isolation of influenza C virus from pigs and experimental infection of pigs with influenza $C$ virus. The Journal of General Virology 64 (Pt 1): 177-182. https://doi.org/10.1099/ 0022-1317-64-1-177.

Hause, B.M., E.A. Collin, R. Liu, B. Huang, Z. Sheng, W. Lu, D. Wang, E.A. Nelson, and F. Li. 2014. Characterization of a novel influenza virus in cattle and Swine: proposal for a new genus in the Orthomyxoviridae family. mBio 5 (2): e00031-e00014. https://doi.org/10.1128/mBio.00031-14.

Hause, B.M., M. Ducatez, E.A. Collin, Z. Ran, R. Liu, Z. Sheng, A. Armien, B. Kaplan, S. Chakravarty, A.D. Hoppe, R.J. Webby, R.R. Simonson, and F. Li. 2013. Isolation of a novel swine influenza virus from Oklahoma in 2011 which is distantly related to human influenza C viruses. PLoS Pathogens 9 (2): e1003176. https://doi.org/10.1371/journal.ppat.1003176.

Heid, C.A., J. Stevens, K.J. Livak, and P.M. Williams. 1996. Real time quantitative PCR. Genome Research 6 (10): 986-994. https://doi.org/10.1101/gr.6.10.986.

Henritzi, D., B. Hoffmann, S. Wacheck, S. Pesch, G. Herrler, M. Beer, and T.C. Harder. 2019. A newly developed tetraplex real-time RT-PCR for simultaneous screening of influenza virus types A, B, C and D. Influenza and Other Respiratory Viruses 13 (1): 71-82. https://doi.org/10.1111/irv.12613.

Khanna, M., B. Kumar, A. Gupta, and P. Kumar. 2012. Pandemic Influenza A H1N1 (2009) virus: lessons from the past and implications for the future. Indian Journal of Virology 23 (1): 12-17. https://doi.org/10.1007/s13337-012-0066-3.

Khanna, M., P. Kumar, K. Choudhary, B. Kumar, and V.K. Vijayan. 2008. Emerging influenza virus: a global threat. Journal of Biosciences 33 (4): 475-482. https:// doi.org/10.1007/s12038-008-0066-z.

Kumar, B., K. Asha, M. Khanna, L. Ronsard, C.A. Meseko, and M. Sanicas. 2018. The emerging influenza virus threat: status and new prospects for its therapy and control. Archives of Virology 163 (4): 831-844. https://doi.org/10.1007/s00705-018-3708-y.

Matsuzaki, Y., N. Katsushima, Y. Nagai, M. Shoji, T. Itagaki, M. Sakamoto, S. Kitaoka, K. Mizuta, and H. Nishimura. 2006. Clinical features of influenza C virus infection in children. The Journal of Infectious Diseases 193 (9): 1229-1235. https://doi.org/10.1086/502973.

Mitra, N., N. Cernicchiaro, S. Torres, F. Li, and B.M. Hause. 2016. Metagenomic characterization of the virome associated with bovine respiratory disease in feedlot cattle identified novel viruses and suggests an etiologic role for influenza D virus. The Journal of General Virology 97 (8): 1771-1784. https:// doi.org/10.1099/jgv.0.000492.

Mostafa, A., E.M. Abdelwhab, T.C. Mettenleiter, and S. Pleschka. 2018. Zoonotic Potential of Influenza A Viruses: A Comprehensive Overview. Viruses 10 (9). https://doi.org/10.3390/v10090497.

Murakami, S., M. Endoh, T. Kobayashi, A. Takenaka-Uema, J.K. Chambers, K. Uchida, M. Nishihara, B. Hause, and T. Horimoto. 2016. Influenza D Virus Infection in Herd of Cattle, Japan. Emerging Infectious Diseases 22 (8): $1517-$ 1519. https://doi.org/10.3201/eid2208.160362.

Nedland, H., J. Wollman, C. Sreenivasan, M. Quast, A. Singrey, L. Fawcett, J. Christopher-Hennings, E. Nelson, R.S. Kaushik, D. Wang, and F. Li. 2018. Serological evidence for the co-circulation of two lineages of influenza $D$ viruses in equine populations of the Midwest United States. Zoonoses and Public Health 65 (1): e148-e154. https://doi.org/10.1111/zph.12423.

Ng, T.F., N.O. Kondov, X. Deng, A. Van Eenennaam, H.L. Neibergs, and E. Delwart. 2015. A metagenomics and case-control study to identify viruses associated with bovine respiratory disease. Journal of Virology 89 (10): 5340-5349. https://doi.org/10.1128/JVl.00064-15.

Olival, K.J., P.R. Hosseini, C. Zambrana-Torrelio, N. Ross, T.L. Bogich, and P. Daszak. 2017. Host and viral traits predict zoonotic spillover from mammals. Nature 546 (7660): 646-650. https://doi.org/10.1038/nature22975.

Pabbaraju, K., S. Wong, A. Wong, J. May-Hadford, R. Tellier, and K. Fonseca. 2013. Detection of influenza $C$ virus by a real-time RT-PCR assay. Influenza and Other Respiratory Viruses 7 (6): 954-960. https://doi.org/10.1111/irv.12099.

Quast, M., C. Sreenivasan, G. Sexton, H. Nedland, A. Singrey, L. Fawcett, G. Miller, D. Lauer, S. Voss, S. Pollock, C.W. Cunha, J. Christopher-Hennings, E. Nelson, and F. Li. 2015. Serological evidence for the presence of influenza D virus in small ruminants. Veterinary Microbiology 180 (3-4): 281-285. https://doi.org/1 0.1016/j.vetmic.2015.09.005.

Salez, N., J. Melade, H. Pascalis, S. Aherfi, K. Dellagi, R.N. Charrel, F. Carrat, and X. De Lamballerie. 2014. Influenza C virus high seroprevalence rates observed in 3 different population groups. The Journal of Infection 69 (2): 182-189. https://doi.org/10.1016/j.jinf.2014.03.016.

Sederdahl, B.K., and J.V. Williams. 2020. Epidemiology and Clinical Characteristics of Influenza C Virus. Viruses 12 (1). https://doi.org/10.3390/v12010089.

Sreenivasan, C., M. omas, Z. Sheng, B.M. Hause, E.A. Collin, D.E. Knudsen, A. Pillatzki, E. Nelson, D. Wang, R.S. Kaushik, et al. 2015. Replication and Transmission of the Novel Bovine Influenza D Virus in a Guinea Pig Model. Journal of Virology 89 (23): 11990-12001. https://doi.org/10.1128/JVI.01630-15.

Taubenberger, J.K., and D.M. Morens. 2006. 1918 Influenza: the mother of all pandemics. Emerging Infectious Diseases 12 (1): 15-22. https://doi.org/10.32 01/eid1201.050979.

Taylor, R.M. 1949. Studies on survival of influenza virus between epidemics and antigenic variants of the virus. American Journal of Public Health and the Nations Health 39 (2): 171-178. https://doi.org/10.2105/ajph.39.2.171.

Thielen, B.K., H. Friedlander, S. Bistodeau, B. Shu, B. Lynch, K. Martin, E. Bye, K. ComoSabetti, D. Boxrud, A.K. Strain, S.S. Chaves, A. Steffens, A.L. Fowlkes, S. Lindstrom, and R. Lynfield. 2018. Detection of Influenza C Viruses Among Outpatients and Patients Hospitalized for Severe Acute Respiratory Infection, Minnesota, 2013-2016. Clinical Infectious Diseases 66 (7): 1092-1098. https:/doi.org/10.1093/cid/cix931.

Treanor, J. 2004. Influenza vaccine--outmaneuvering antigenic shift and drift. The New England Journal of Medicine 350 (3): 218-220. https://doi.org/10.1056/ NEJMp038238. 
Urbaniak, K., and I. Markowska-Daniel. 2014. In vivo reassortment of influenza viruses. Acta Biochimica Polonica 61 (3): 427-431.

White, S.K., W. Ma, CJ. Mcdaniel, G.C. Gray, and J.A. Lednicky. 2016. Serologic evidence of exposure to influenza D virus among persons with occupational contact with cattle. Journal of Clinical Virology 81: 31-33. https:/doi.org/10.1016/j.jcv.2016.05.017.

Yen, H.L., A.S. Lipatov, N.A. llyushina, E.A. Govorkova, J. Franks, N. Yilmaz, A. Douglas, A. Hay, S. Krauss, J.E. Rehg, E. Hoffmann, and R.G. Webster. 2007. Inefficient transmission of H5N1 influenza viruses in a ferret contact model. Journal of Virology 81 (13): 6890-6898. https://doi.org/10.1128/JVI.00170-07.

Yuanji, G., and U. Desselberger. 1984. Genome analysis of influenza C viruses isolated in 1981/82 from pigs in China. The Journal of General Virology 65 (Pt 11): 1857-1872. https://doi.org/10.1099/0022-1317-65-11-1857.

Zhai, S.L., H. Zhang, S.N. Chen, X. Zhou, T. Lin, R. Liu, D.H. Lv, X.H. Wen, W.K. Wei, D. Wang, and F. Li. 2017. Influenza D Virus in Animal Species in Guangdong Province, Southern China. Emerging Infectious Diseases 23 (8): 1392-1396. https://doi.org/10.3201/eid2308.170059.

Zhang, H., E. Porter, M. Lohman, N. Lu, L. Peddireddi, G. Hanzlicek, D. Marthaler, X. Liu, and J. Bai. 2018. Influenza C Virus in Cattle with Respiratory Disease, United States, 2016-2018. Emerging Infectious Diseases 24 (10): 1926-1929. https://doi.org/10.3201/eid2410.180589.

Zhu, H., D. Wang, D.J. Kelvin, L. Li, Z. Zheng, S.W. Yoon, S.S. Wong, A. Farooqui, J. Wang, D. Banner, R. Chen, R. Zheng, J. Zhou, Y. Zhang, W. Hong, W. Dong, Q. Cai, M.H.A. Roehrl, S.S.H. Huang, A.A. Kelvin, T. Yao, B. Zhou, X. Chen, G.M. Leung, L.L.M. Poon, R.G. Webster, R.J. Webby, J.S.M. Peiris, Y. Guan, and Y. Shu. 2013. Infectivity, transmission, and pathology of human-isolated H7N9 influenza virus in ferrets and pigs. Science 341 (6142): 183-186. https://doi. org/10.1126/science.1239844.

\section{Publisher's Note}

Springer Nature remains neutral with regard to jurisdictional claims in published maps and institutional affiliations.

Ready to submit your research? Choose BMC and benefit from:

- fast, convenient online submission

- thorough peer review by experienced researchers in your field

- rapid publication on acceptance

- support for research data, including large and complex data types

- gold Open Access which fosters wider collaboration and increased citations

- maximum visibility for your research: over $100 \mathrm{M}$ website views per year

At $\mathrm{BMC}$, research is always in progress.

Learn more biomedcentral.com/submissions 